\title{
Development of a color calendar for food colors using natural colors
}

\section{By}

Akmeemana Palliya Guruge Vijayanthi Chandramali

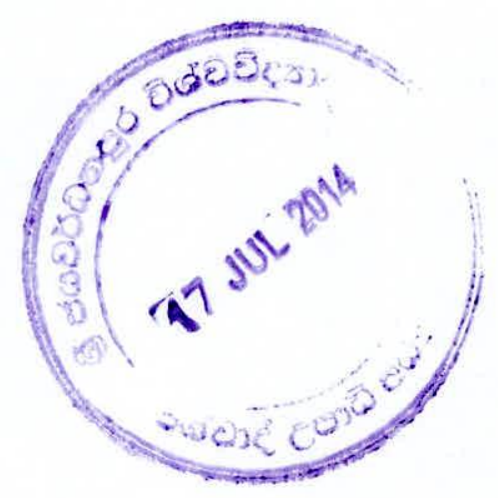

M. Sc. 


\section{Development of a color calendar for food colors using natural colors}

By

Akmeemana Palliya Guruge Vijayanthi Chandramali

Thesis submitted to the University of Sri Jayewardenepura for the award of the degree of Master of Science in Food Science and Technology on 2010. 


\section{Declaration}

"The work describe in this thesis was carried out by me as a project in The Department of Food Science and Technology,University of Jayewardenepura under the supervision of Dr.S.B. Navarathne and A report on this thesis has not been submitted in whole or in part to any University or any other institution for another degree."

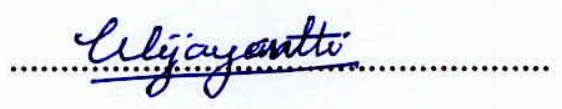

A.P.G.W.Chandramali 
We Dr.S.B.Navarathne certify that the statement in the proceeding page made by the candidate is true and that this thesis is suitable for submission for the University for the purpose of evaluation.

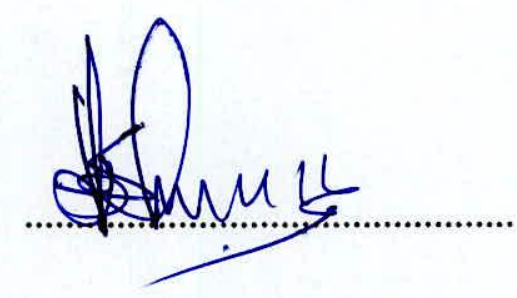

(Internal supervisor)

Dr. S.B.Navarathne

\section{Senior Lecturer}

Department of Food Science and Technology

University of SriJayawardenapura 


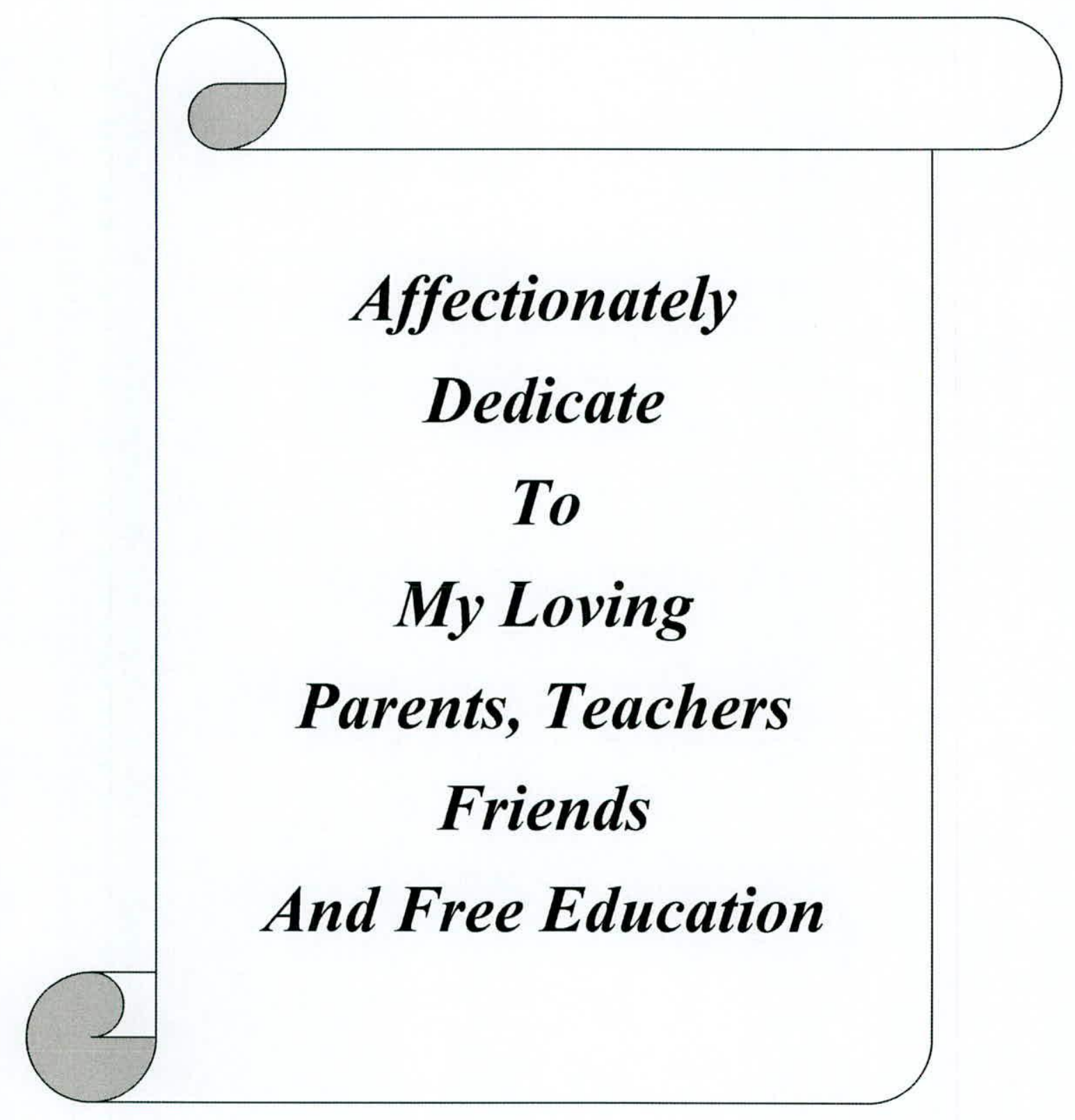




\begin{abstract}
Colorants are characterized by their ability to absorb visible part of the electromagnetic spectrum $(380-780 \mathrm{~nm})$ For good colouring propertyit has to have enough absorption co-efficient $(10000$ to $40000 \mathrm{lmol}^{-1} \mathrm{~cm}^{-1}$ ) Also it must have properties enabling it to keep with colored material and stability.As a rule colourants nowadays have to be harmless.Many dyes have been extracted traditionally from roots,berries,flowers,barks and leaves.Common natural colorings include annato,saffron,paprika,grapes skin,caramel,beetroot,cochineal and turmeric.The objectives $f$ the study are Identification of edible grade different plant based pigment sources,classification of pigment sources according to chemical composition and morphology,development of extraction methods,monitoring stability of the pigments under different food processing condition,monitoring stability of the color with respect to shelf life,selection of best compatible color for appropriate food product.
\end{abstract}

In this research as a lower based material used hibiscus, citoria,ranawara,rathmal,buthsarana,bell fruit flower.Also as a plant based material used mango,jackfruit,pomengranate,passionfruit. According to the chemical composition ranawara and mango include carotenoides, hibiscus include flavanoides and clitoria include betalines.

Due to water solubility of hibiscus and clitoria for extraction purpose used water extraction method.Due to fat solubility of ranawara for extraction purpose used ethanol extraction method.

By using hibiscus $3 \mathrm{~g}$ could extract $30 \%$ percentage of colour $(0.906 \mathrm{~g})$ By using $5 \mathrm{~g}$ of hibiscus could extract $18 \%$ percentage of colour $(0.05 \mathrm{~g})$ By using $3 \mathrm{~g}$ of clitoria could extract $8 \%$ percentage of colour $(0.24 \mathrm{~g})$. By using $5 \mathrm{~g}$ of clitoria could extract $22 \%$ percentage of colour (1.14g). By using $3 \mathrm{~g}$ of ranawara could extract $38 \%$ percentage of colour $(1.16 \mathrm{~g})$. By using $5 \mathrm{~g}$ of ranawara could extract $5 \%$ percentage of colour $(0.25 \mathrm{~g})$.

With increasing $\mathrm{pH}$ from 1-10 color intensity of hibiscus varies from dark red to colorless.It means hibiscus shows dark red color in acidic medium.For clitoria with increasing $\mathrm{pH}$ from 1-10 color intensity varies from light blue to dark blue. It means clitoria shows dark blue color in base medium.Those shows the properties/characters of the indicators. 
Extracted color in liquid form stored in refrigerator at $4{ }^{0} \mathrm{c}$ could kept for 6 weeks. This shelf life was lengthened up to 8 weeks after applied citric acid to the liquid form. Also powdery form could kept for 10 weeks after sealed it.

Jam and RTS drink were made by using natural brown color extracted by bell fruit flowers. It was get nice brown color appearance very close to company made RTS product and jam. After application of blue, yellow and pink colors to the icing sugar it takes beautiful color appearance of it. 


\section{ACKNOWLEDGEMENTS}

I would like to express profound gratitude to Dr. S.B.Nawarathna, Senior Lecturer, Department of Food Science and Technology, University of Sri Jayewardenepura and Professor K.K.D.S.Ranaweera, Senior Lecturer, Dept. of Food Science and Technology, University of Sri Jayawardenepura for giving me this greatest opportunity to conduct this project.

I wish to express my appreciation to Dr. P.R.D.Perera, Senior Lecturer, Department of Food Science and Technology, University of Sri Jayewardenepura, Dr. Indira Wickramasinghe, Head of the department \& Senior Lecturer, Department of Food Science and Technology, University of Sri Jayewardenepura, for their support, valuable advices and encouragement given during my project. Also I like to thank lab technologist Mr. Shanaka Karunarathne, and lab assistant Mr.B.P.Rupasinghe for their support.

I am as ever especially indebted to my parents, brother \& friends, for their love and support throughout my project.

Lastly I offer my regards and blessings to all of those who supported me in any respect during the completion of the project. 


\section{TABLES OF CONTENTS}

\section{Page}

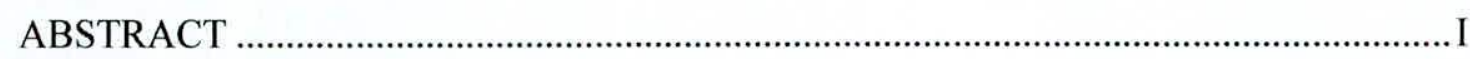

ACKNOWLEDGEMENTS............................................................................................ III

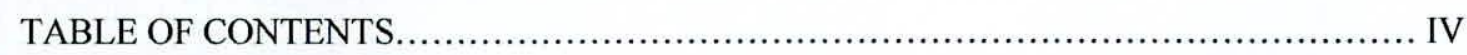

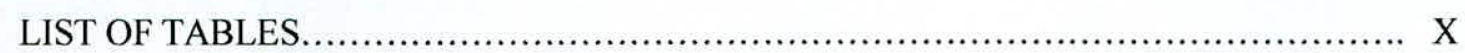

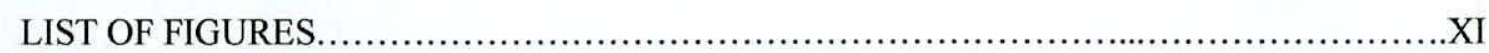

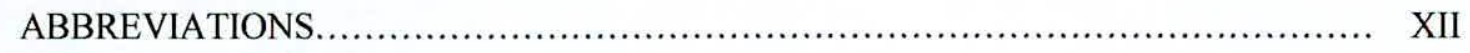

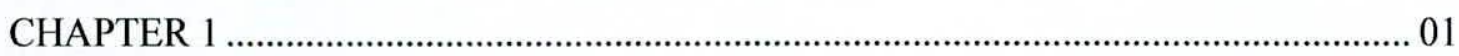

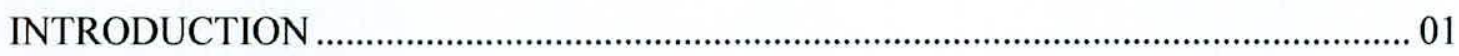

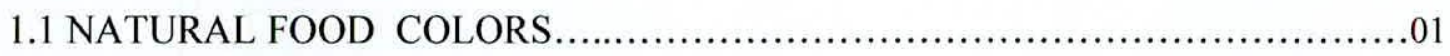

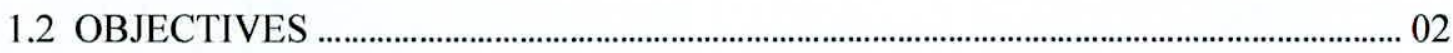

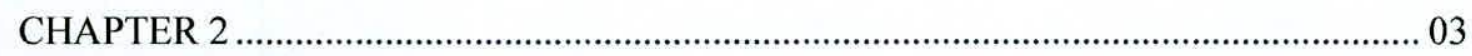

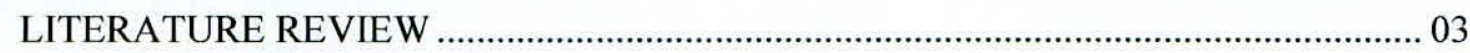

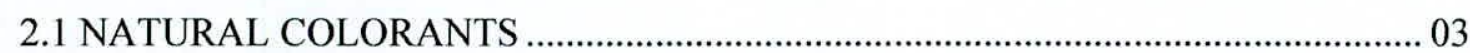

2.2 NATURAL COLORANTS, SOME TYPICAL EXAMPLES ………………………..... 03

2.2 .1 Red

2.2 .2 Blue

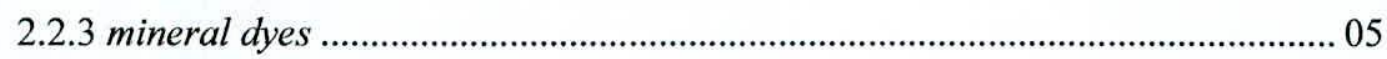

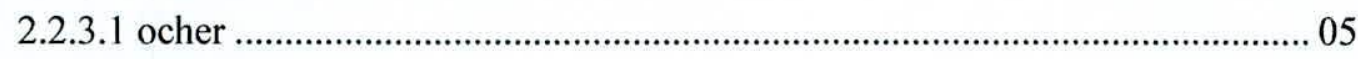

2.2.3.2 chromophore 


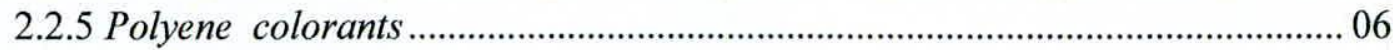

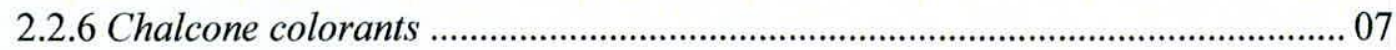

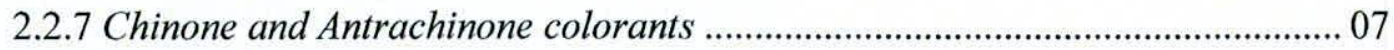

2.2.7.1 Biologically Active Natural Compounds ................................................... 07

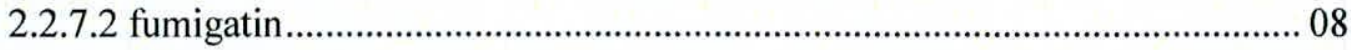

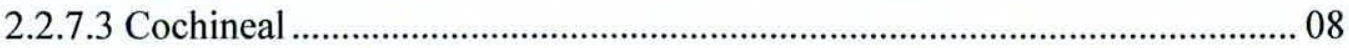

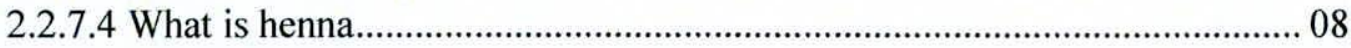

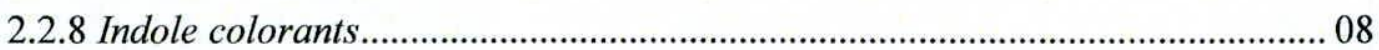

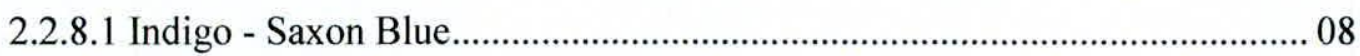

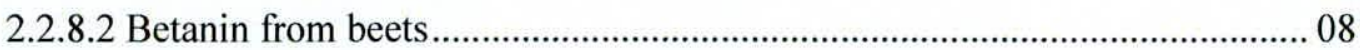

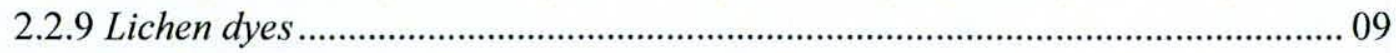

2.3 THE WORLD OF NATURAL FOOD COLORS................................................. 09

2.3.1 Food colours - why do we need them? ................................................................. 09

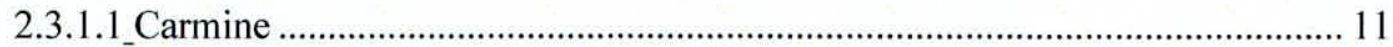

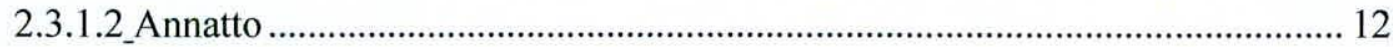

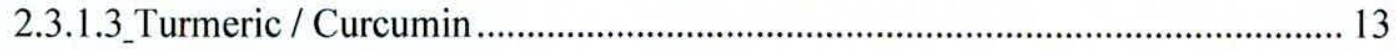

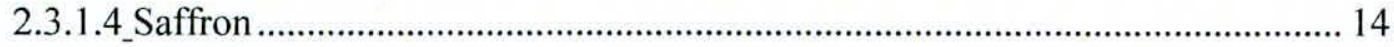

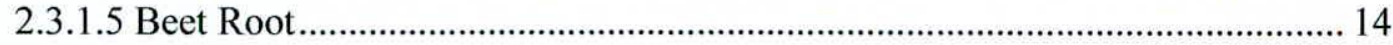

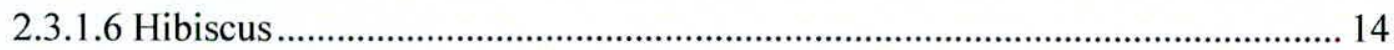

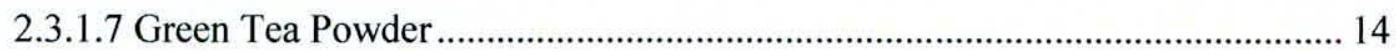

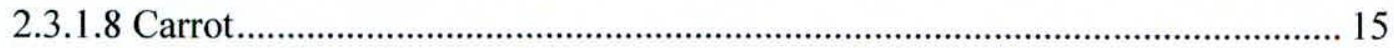

2.3.1.9 Grape Anthocyanins / Grape skin extract..................................15

2.4 HOMEMADE NATURAL PINK FOOD COLOUR ............................................... 16

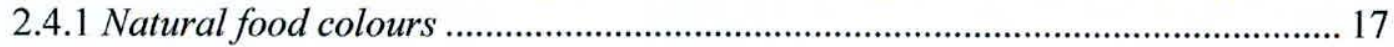




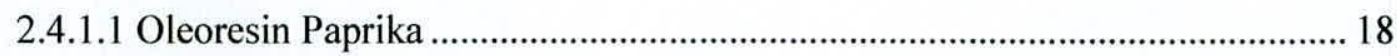

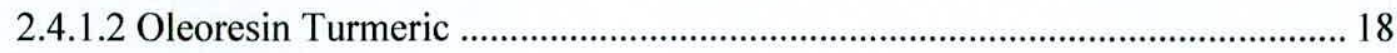

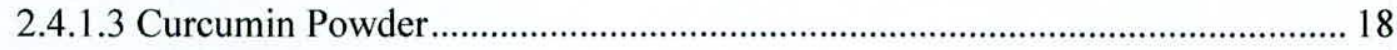

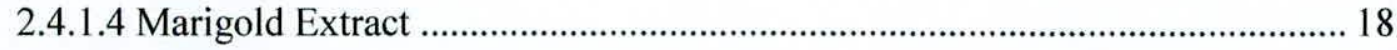

2.5 PIGMENT EXTRACTS IN PLANT LIPIDS .............................. 18

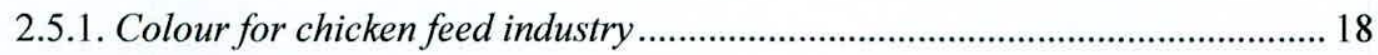

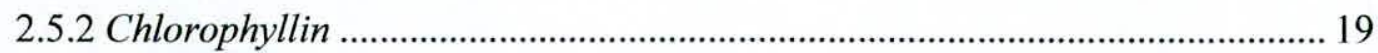

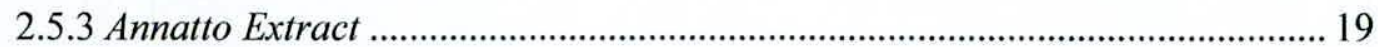

2.6 EXTRACTION OF CHERRIES WITH 45\% ETHANOL IN WATER............. 20

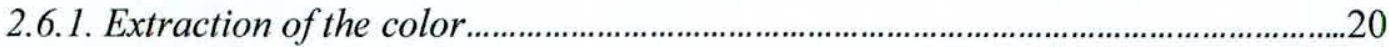

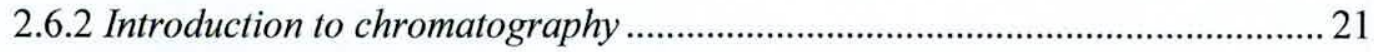

2.7. SAY pH WITH FLOWERS, FRUITS, AND VEGETABLES ............................ 23

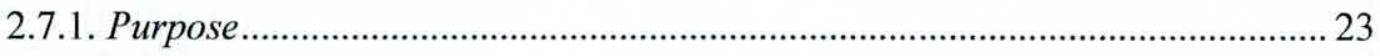

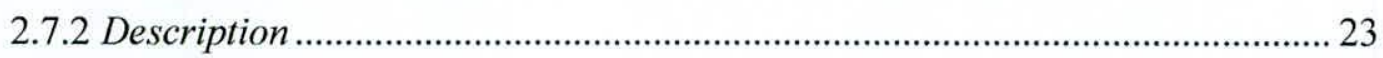

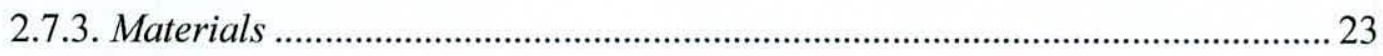

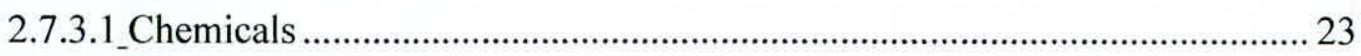

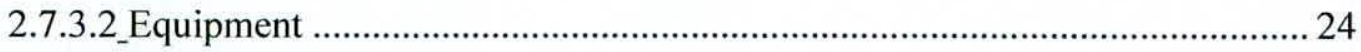

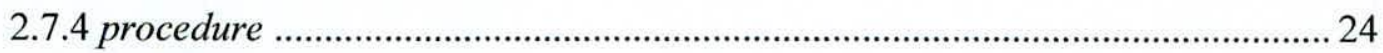

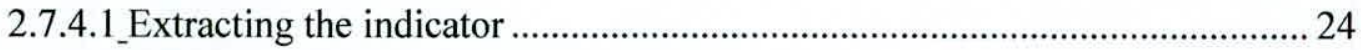

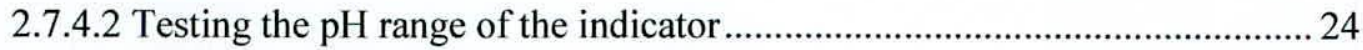

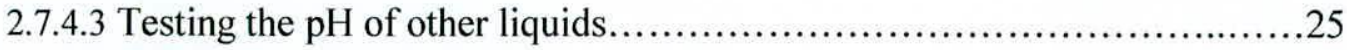

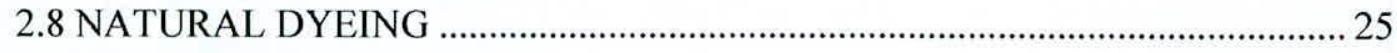

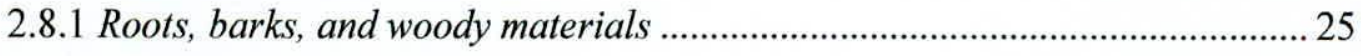

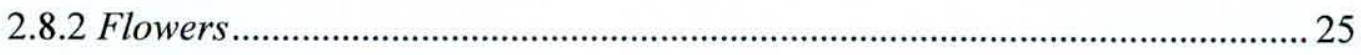

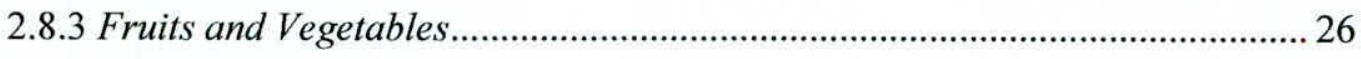




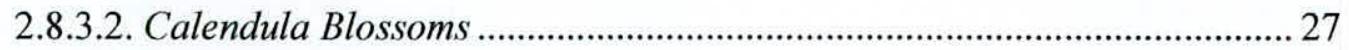

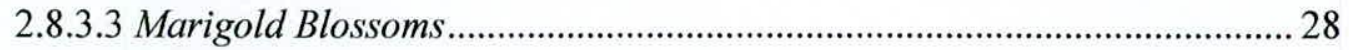

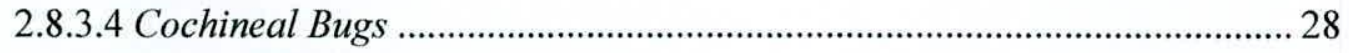

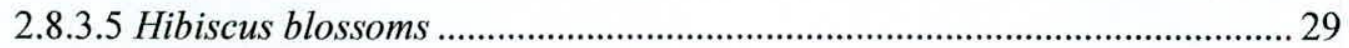

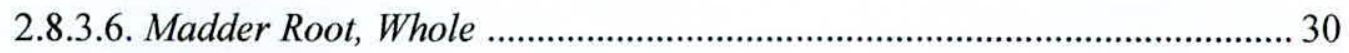

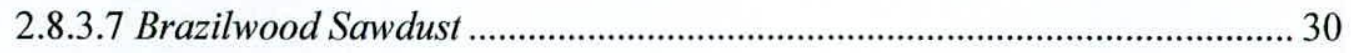

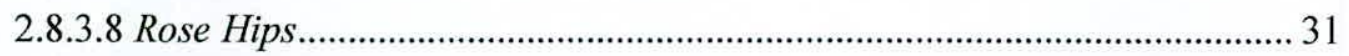

2.9 DEVELOPING MULTIPLE NATURAL DYES FROM FLOWER PARTS OF

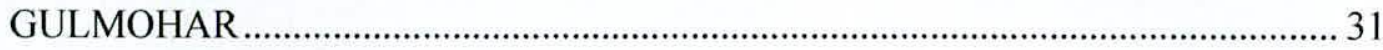

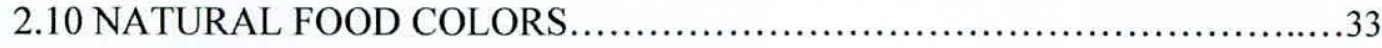

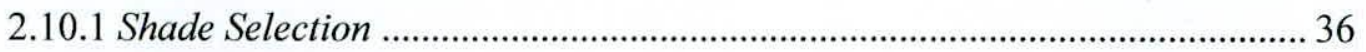

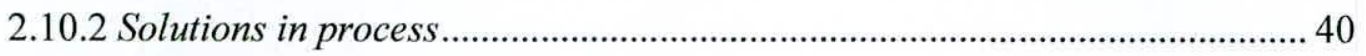

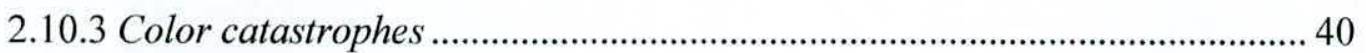

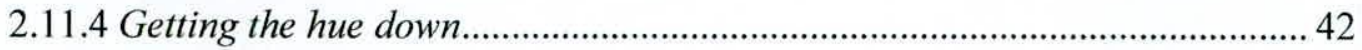

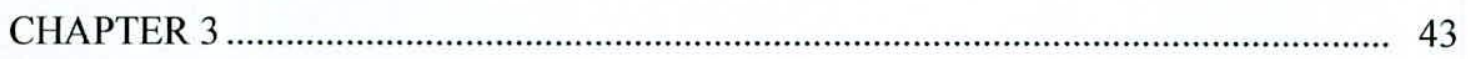

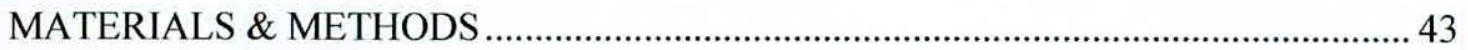

3.1IDENTIFICATION OF EDIBLE GRADE DIFFERENT PLANT BASED PIGMENT

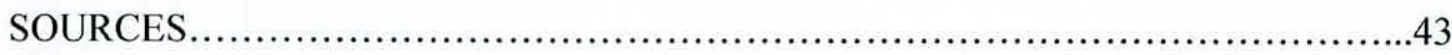

3.2. CLASSIFICATION OF PIGMENT SOURCES ACCORDING TO CHEMICAL COMPOSITION

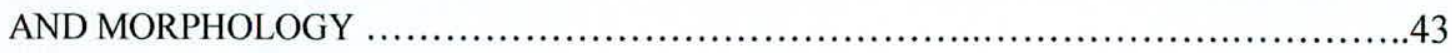

3.3 DEVELOPMENT OF EXTRACTION METHODS .......................................................43

3.3.1 Water extraction method. ....................................................43 
3.3.2 Alcohol extraction method

3.4 MONITORING STABILITY OF THE PIGMENTS UNDER DIFFERENT FOOD PROCESSING CONDITION.

3.5MONITORING STABILITY OF THE COLOR WITH RESPECT TO SHELF LIFE..45

3.6.1 Jam making procedure

3.6.2 Production of fruit cordial

3.6.3 Sensory evaluation 46

3.7 COMPARISON WITH ARTIFICIAL COLOR WITH RESPECT TO ABSORPTION CHROMATOGRAPHY

3.7.1_Method ofspectrophotometer....

3.8 DEVELOPMENT OF COLOR CALENDAR USING EXTRACTED COLORS. ...... 48

CHAPTER 04 .49

RESULTS \& DISCUSSION 49

4.1IDENTIFICATION OF EDIBLE GRADE DIFFERENT PLANT BASED PIGMENT SOURCES.

4.2. CLASSIFICATION OF PIGMENT SOURCES ACCORDING TO CHEMICAL COMPOSITION AND MORPHOLOGY

4.2.1 Classification of pigment sources according to chemical composition and morphology49

4.2.2 Segregation of identified plants by the study....

4.2.3 List of plants identified by the survey for pigment extraction 49

4.2.4 List of Approximate pigment extractability economical state and color composition of the component.

4.2.5 Classification of plant with respect to biological,chemical, \& heat stability of the extract. 


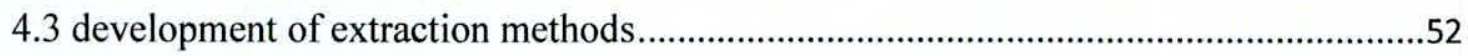

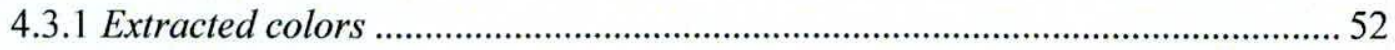

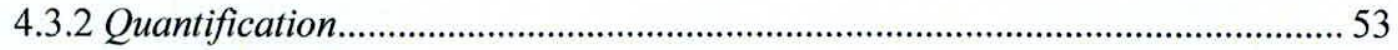

4.4 Monitoring stability of the pigments under different food processing condition......... 53

4.5 Monitoring stability of the color with respect to shelf life............................................54

4.6 Selection of best compatible color for appropriate food product .................................. 54

4.7 COMPARISON WITH ARTIFICIAL COLOR WITH RESPECT TO ABSORPTION

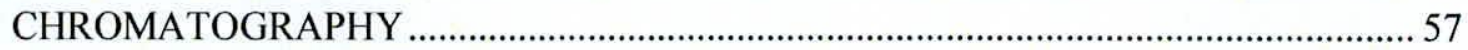

4.7.1_Method ofspectrophotometer..............................................57

4.8 DEVELOPMENT OF COLOR CALENDAR USING EXTRACTED COLORS. ..... 60

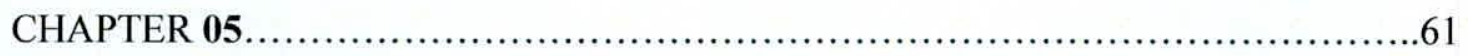

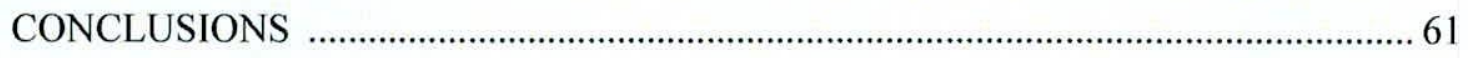

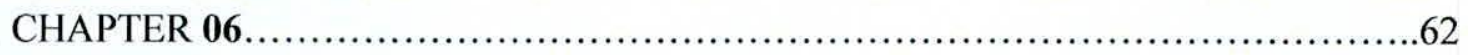

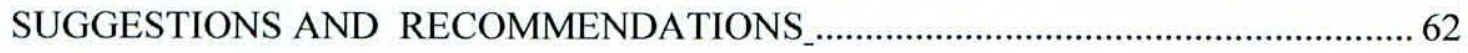

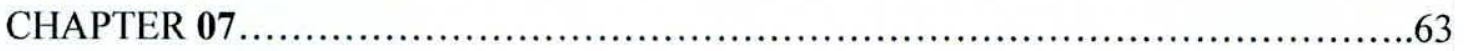

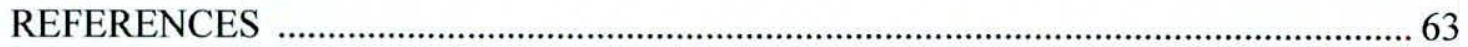

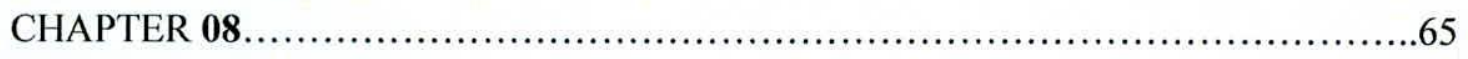

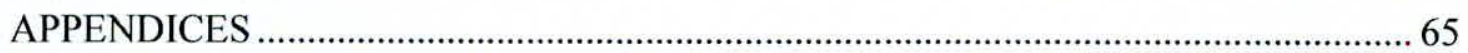




\section{LIST OF TABLES}

Table 4.1 Classification of plants in accordance with their properties............................... 52

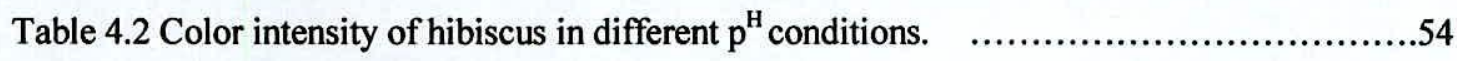

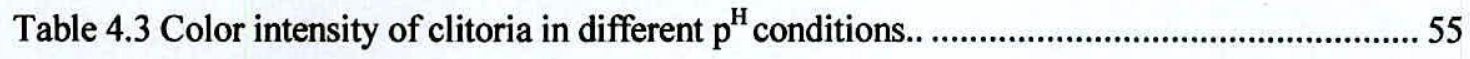

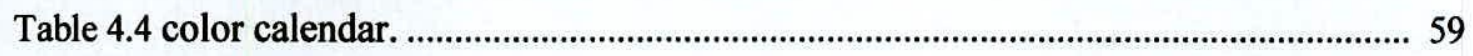

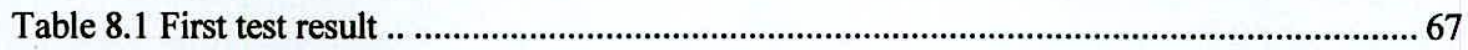

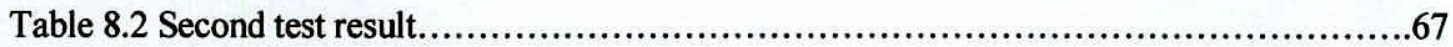

